\title{
Efficient lamp design for office or personal cubicles.
}

\author{
Jonny Carmona Reyes ${ }^{1}$, Elisur Prado Luna ${ }^{1}$, Alan Carmona López ${ }^{1}$, Brenda Bonilla Zetina ${ }^{1}$ \\ Technological University of Tlaxcala, Industrial Maintenance Engineering \\ DOI: 10.29322/IJSRP.10.11.2020.p10760 \\ http://dx.doi.org/10.29322/IJSRP.10.11.2020.p10760
}

\begin{abstract}
This document presents the study that was conducted on two electric lamps, one square lamp of $25 \mathrm{w}$ at $120 \mathrm{volts}$ and the other, a ring light at $14 \mathrm{w}$ at 5 volts. It was documented and demonstrated by analyzing two variables, one concerning the electric consumption with an electric current analysis circuit during the operation period, comparing the power output of both lamps and the second regarding the analysis of light intensity (lumens) with an electric circuit including a LDR photoresistor, to value which lamp delivers more light intensity.
\end{abstract}

Once data on both issues of electricity consumption and lighting were obtained, the studies were contrasted graphically, comparing which lamp delivers more lumens with less current as well as verifying which is the most efficient.

Index Terms- Illumination, Luxes, Saving, Stream

\section{Introduction}

The purpose of this study is to evaluate the consumption of lighting and current to make the lighting system as efficient as possible, having a projection to the environment, showing the importance and use of renewable energy by using photovoltaic panels or in the subsequent case, make a change of lamps to minimize power consumption and increase the lighting.

The advantages of having electrical energy in the form of alternating current are diverse:

- The profit and benefits are focused on the non consumption of commercial energy.

- The use of renewable energy that, in this case, is produced by solar panels, taking into account that there is an improvement benefit for the environment.

- Economic care (less money consumption).

With the previous project investigations that were carried out, the value of both consumptions of energy was known. It's more efficient to have a system of energy that limits the commercial consumption, but the quality of the illumination will be maintained and the lamps used are led lamps, having a better efficiency according to the quality of energy. We will stop using this commercial consumption thanks to the research. With this project, we hope that in the future the implementation of this kind of lamps will be achieved.

\section{Theoretical framework}

The history of energy begins since the remote times where mankind started to rub stones together to obtain fire, improve their livelihood, as well as to survive. It is here where the man realizes that energy arises, noticing that through time, it has been a great benefit for the society, such as the electrical energy, energy applied to industrial processes, energy used in means of transport, among others. Energy also occupies a

very important role in the scientific and technological advances that benefit humanity. [1]

The oil crisis began in October 16th, 1973, which, given the increase in price coupled with the world's dependence on oil, caused an inflationary effect and a reduction in economic activity, having the use of energy as subsequent demand. [2] 
According to the research carried out, lamps have a contribution against climate change. In Mexico, about a fifth of the energy produced is destined to domestic lighting by means of incandescent electric bulbs. These lamps are an excellent technology for saving energy compared to incandescent bulbs (they can consume up to $75 \%$ less energy) and have a longer useful life.

In this type of areas with an illumination of 400 to 550 lumens is more than enough, it could be observed that a great change in energy consumption and efficiency levels would be much better. Evaluating the correct lighting levels in order to establish optimal requirements in each and every one of the areas in work centers is an obligation of the companies, or employers, and it's included in the current regulation NOM 025-STPS-2008 of the Labor Secretary. This regulation seeks to control the right lighting in work centers for a correct performance of the functions of each worker, in a safe and healthy environment. The regulation contemplates the obligations that the company or the employer has regarding the lighting conditions of work centers. Some of them are:

- Control the optimal lighting levels in work areas, according to the stipulations of the regulations depending on the place where the tasks are performed, the lighting can range from $20 \mathrm{~lx}$, such as in outdoor areas (patios or parking lots) to $2,000 \mathrm{~lx}$ in activities that require a high degree of specialization in distinguishing details (within workshops where small parts are worked on for very long periods).

- Practice annual exams of visual acuity, campimetry and color perception to the workers that develop their activities in areas of the work center that have special illumination. [3]

Table 1 LIGHTING LEVELS / Secretary of Labor and Social Security

\begin{tabular}{|c|c|c|}
\hline Visual Task of the Job & Work Area & $\begin{array}{l}\text { Minimum } \\
\text { Lighting } \\
\text { Levels (lx) }\end{array}$ \\
\hline $\begin{array}{l}\text { Outdoors: distinguish the transit area, walking, } \\
\text { surveillance, vehicle movement. }\end{array}$ & General exteriors: patios and parking lots & 20 \\
\hline $\begin{array}{l}\text { Indoors: distinguish the transit area, walking, } \\
\text { surveillance, vehicle movement. }\end{array}$ & $\begin{array}{l}\text { General interiors: low-movement } \\
\text { warehouses, corridors, staircases, } \\
\text { covered parking lots, subway mine } \\
\text { works, emergency lighting. }\end{array}$ & 50 \\
\hline Indoors. & $\begin{array}{l}\text { Circulation areas and corridors; waiting } \\
\text { rooms; restrooms; storage rooms; } \\
\text { platforms; boiler rooms }\end{array}$ & 100 \\
\hline $\begin{array}{l}\text { Personnel Services: rough storage, reception and } \\
\text { dispatch, surveillance booths, compressor rooms and } \\
\text { coppersmith. }\end{array}$ & $\begin{array}{l}\text { Personnel Services: rough storage, } \\
\text { reception and dispatch, surveillance } \\
\text { booths, compressor rooms and } \\
\text { coppersmith. }\end{array}$ & 200 \\
\hline $\begin{array}{l}\text { Moderate distinction of details: simple assembly, } \\
\text { medium bench and machine work, simple inspection, } \\
\text { packaging and office work. }\end{array}$ & $\begin{array}{l}\text { Workshops: packaging and assembly } \\
\text { areas, classrooms and offices }\end{array}$ & 300 \\
\hline $\begin{array}{l}\text { Clear distinction of details: delicate machining and } \\
\text { finishing, moderately difficult inspection assembly, } \\
\text { information capture and processing, handling of } \\
\text { instruments and laboratory equipment. }\end{array}$ & $\begin{array}{l}\text { Precision workshops: computer rooms, } \\
\text { drawing areas, laboratories. }\end{array}$ & 500 \\
\hline
\end{tabular}


Commercially, we have a great variety of lamps in different powers (Illustration 1) In the investigation carried out by our work team, the existence of polluting harmonics in the electrical power network with this type of equipment is shown, which confirms the investigation previously carried out. [4]. [1].

\begin{tabular}{|c|c|c|c|c|}
\hline LOMENES & LED & FLUERESCENTES & HALOGENAS & INCANDESCENTES \\
\hline $80 / 90$ & $1 \mathrm{~W}$ & - & - & $10 \mathrm{w}$ \\
\hline $240 / 270$ & $3 w$ & - & - & $20 \mathrm{w}$ \\
\hline $400 / 450$ & $5 \mathrm{~W}$ & - & - & $35 \mathrm{~W}$ \\
\hline $560 / 630$ & $7 \mathrm{~W}$ & - & $29 \mathrm{w}$ & $50 w$ \\
\hline $800 / 900$ & 10w & $20 \mathrm{~W}$ & $40 \mathrm{w}$ & $80 \mathrm{~W}$ \\
\hline $960 / 1080$ & $12 \mathrm{w}$ & $24 W$ & $49 \mathrm{w}$ & $100 \mathrm{~W}$ \\
\hline $1200 / 1350$ & $15 \mathrm{w}$ & $30 w$ & $62 \mathrm{~W}$ & $120 \mathrm{~W}$ \\
\hline $1600 / 1800$ & $20 \mathrm{w}$ & 40W & $80 \mathrm{~W}$ & I50w \\
\hline $4800 / 5400$ & Gow & $120 \mathrm{~W}$ & $250 \mathrm{~W}$ & $400 w$ \\
\hline $6400 / 7200$ & $80 \mathrm{w}$ & $160 \mathrm{~W}$ & $330 \mathrm{w}$ & $450 \mathrm{~W}$ \\
\hline $7200 / 8100$ & sow & $180 \mathrm{~W}$ & $370 \mathrm{w}$ & $550 \mathrm{w}$ \\
\hline $9600 / 10080$ & $120 \mathrm{w}$ & $240 \mathrm{~W}$ & $500 \mathrm{w}$ & J50w \\
\hline $12000 / 13500$ & $150 \mathrm{w}$ & $300 \mathrm{~W}$ & $620 \mathrm{~W}$ & $900 \mathrm{~W}$ \\
\hline $13800 / 14400$ & $160 \mathrm{w}$ & $320 \mathrm{~W}$ & $663 \mathrm{~W}$ & $950 \mathrm{~W}$ \\
\hline $\begin{array}{c}\text { AHORRO } \\
\text { ENERGETICO }\end{array}$ & - DE $80 \%$ & + DE $60 \%$ & + DE $30 \%$ & $0 \%$ \\
\hline
\end{tabular}

Table 2 Equivalence table / lacasadelalampara

According to a study briefly carried out by us, it was confirmed that in our institution we are consuming a lot of energy unnecessarily, because according to the NOM 025-STPS-2008 standard, we are consuming more energy than necessary for a study area or a small area $\left(2 * 3 \mathrm{~m}^{2}\right)$, since we have high-power lamps and they are delivering more lumens than necessary, we looked for the best lamps and types of light bulbs for our home, in addition to helping us reduce consumption of energy, have less harmonics and better or equal lighting. The survey was conducted with 117 people to determine the use of energy-saving lamps in their homes, of which $91 \%$ of them use energy-saving lamps of $25-35 \mathrm{~W}$ at home, the equivalent of $45 \%$ of the respondents said that they used them to illuminate small areas with measurements of $3 \times 2$ square meters, based on the data obtained and the the analysis systems studies carried out on the consumption and the intensity of light (lumens).

We can define electrical disturbances as perturbations that occur in any electrical system, which not necessarily reflect the absence of voltage, but rather manifest as variations in the voltage waveform and affect the operation of various types of equipment connected to the system, or, in other words, any disturbance in electrical power systems that manifests itself in deviations from the proper voltage, current or frequency conditions, which can result in equipment malfunction or misoperation. 
It refers to the supply of energy to elements, equipment and electrical or electronic devices, with the appropriate characteristics and conditions, allowing them to maintain their continuity without affecting their performance or causing a component failure. Electrical energy is considered a necessary element in daily life; therefore, it is essential to have an uninterrupted quality supply, without generating contamination in electrical energy.

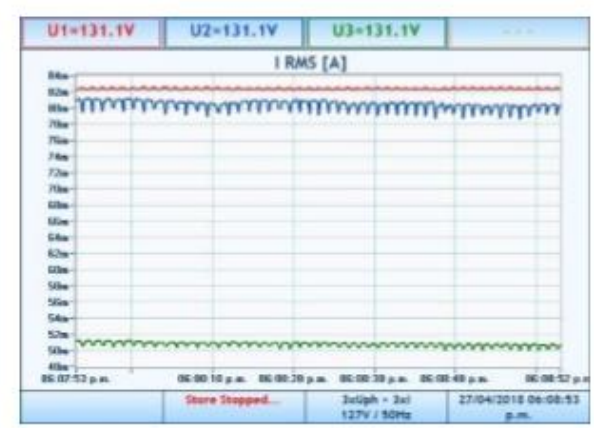

a)

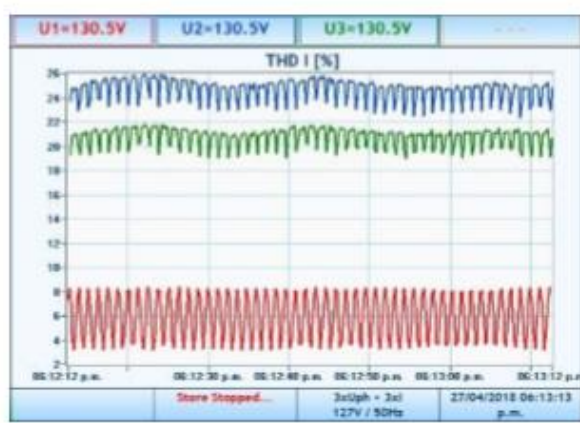

b)

Illustration 1 Current Graphs / [1].

The schedule change implemented in 1996, largely allows the reduction of electricity consumption during the months of April to October, as shown in table 4.

We propose a design that is functional and meets many of the lighting requirements requested by society. A survey was conducted on 117 people, of whom, about 91\% use energy-saving light bulbs, and $45 \%$ of these want to illuminate a small indoor area.

\section{Methodology:}

Our 12-led lamp design with power switching allows for a wide range of lighting with the same amount of lumens and lower power consumption.

Comparative charts according to the current regulations NOM 025-STPS-2008

The first graph shows the illumination capacity of 6 LEDs and / or energy consumption to verify which goes according to our needs.

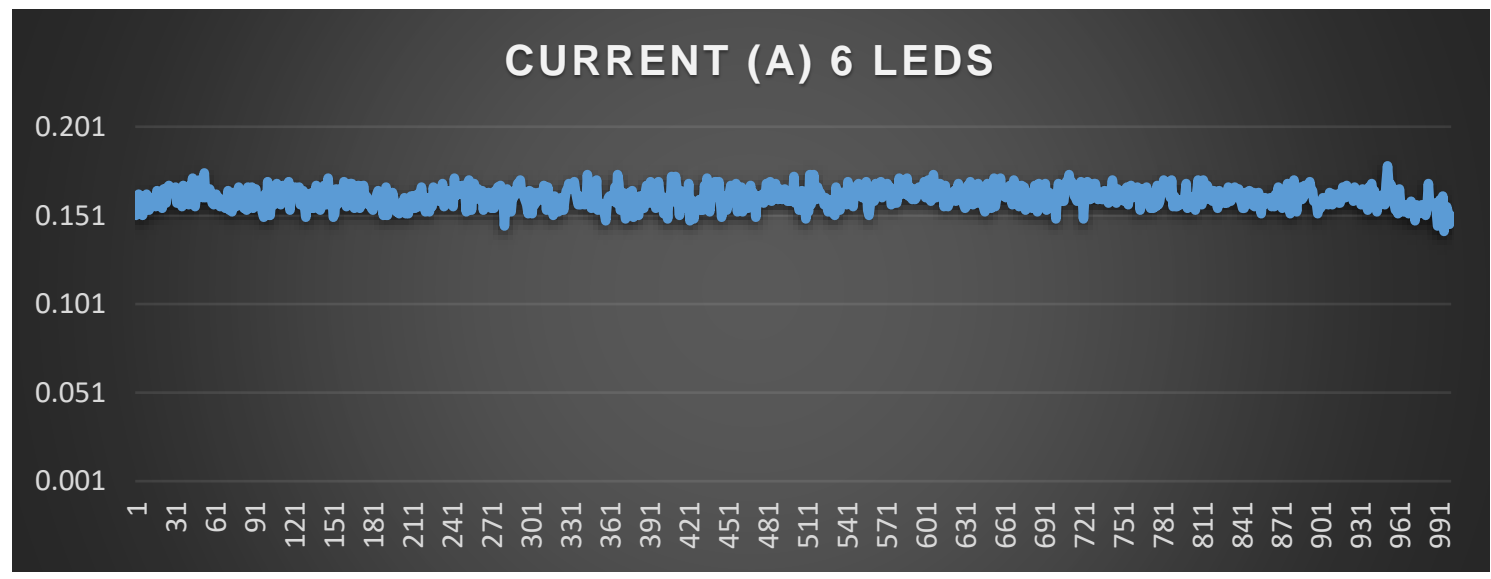

2 Current Graqh in 6 leds / own source

The following graph shows the amount of Watts consumed by a 6 LED lamp, taking into account that the oscillation has a very marked variation. 


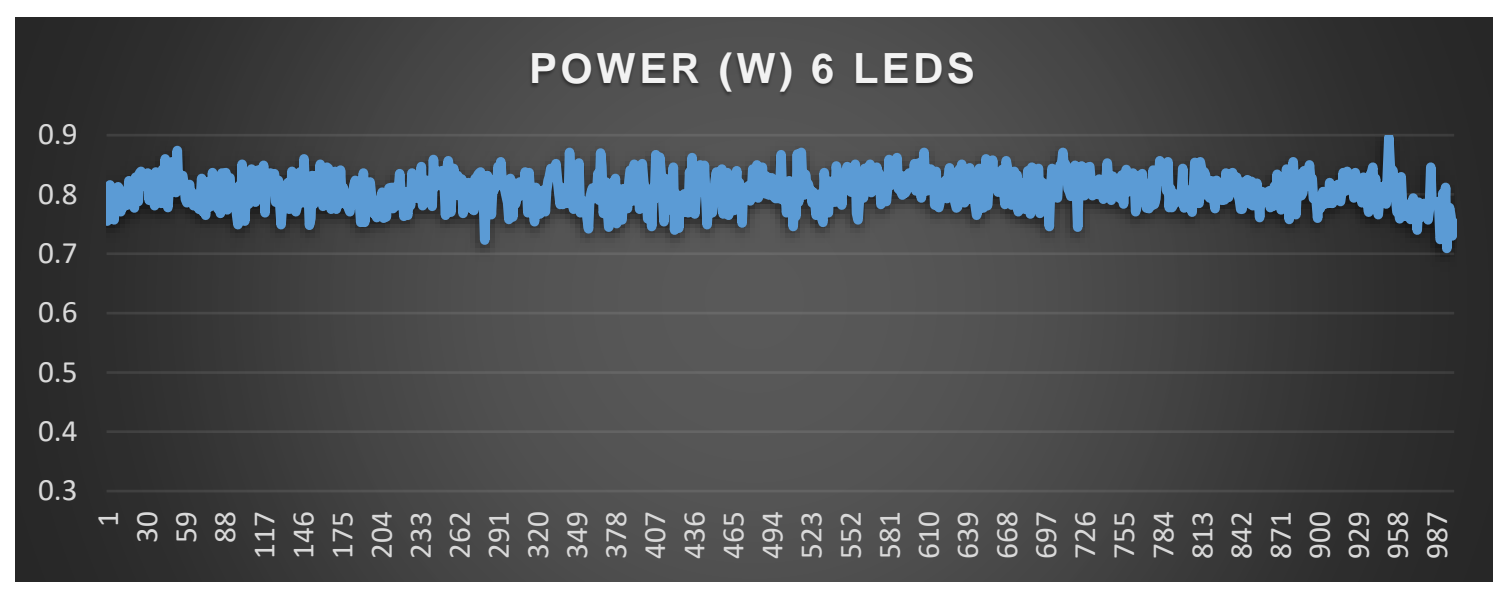

3 own source / Graph in watts of 6 leds

The next graph aims to show the amount of luxes consumed by the lamps having a variation of 6 leds, obtaining graphic data that the 12 led lamp has a continuous consumption.

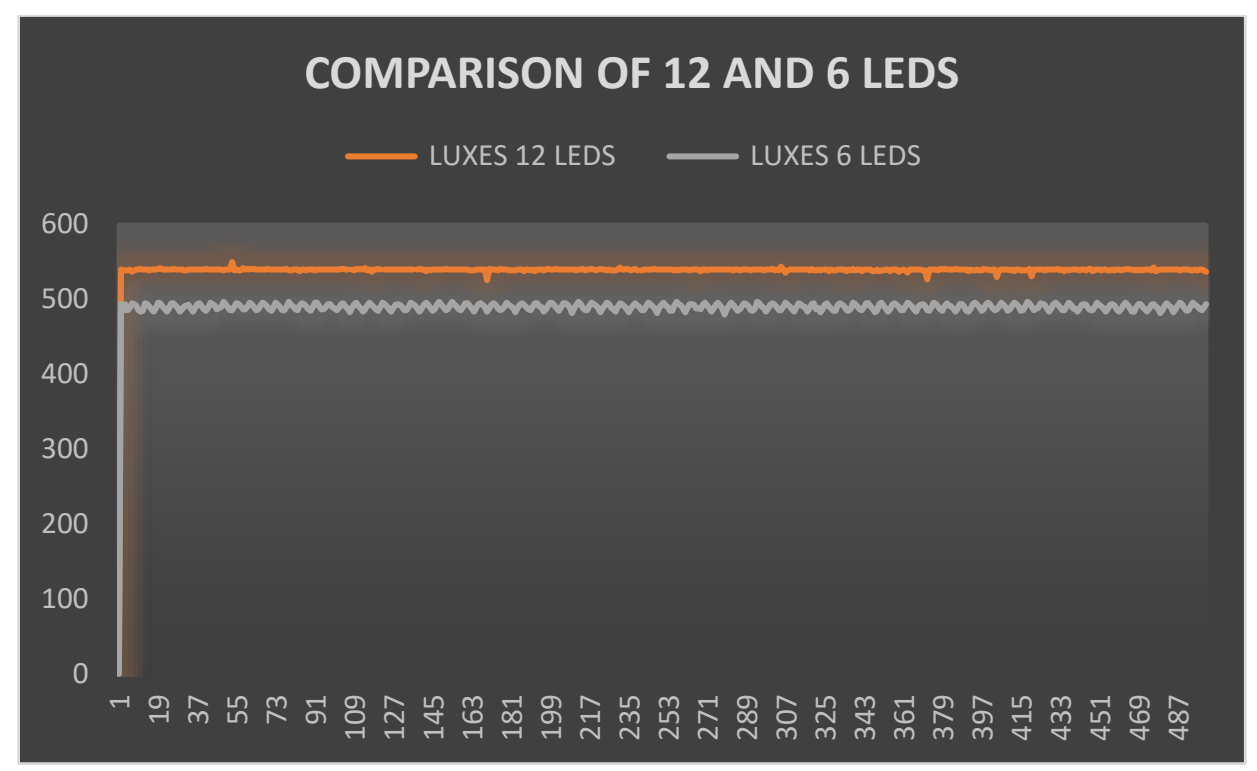

4Graph of 6 and 12 LED lamp consumption of luxes / Own power

Comparison of the current in both lamps obtained through a circuit with which we can graph the power of the lamp and make a decisive study to make the appropriate changes to obtain real values by which we can graph and act to make comparisons and determinant changes. The oscillation that exists in the current of 12 LEDs of the lamp having more consumption is shown here. 


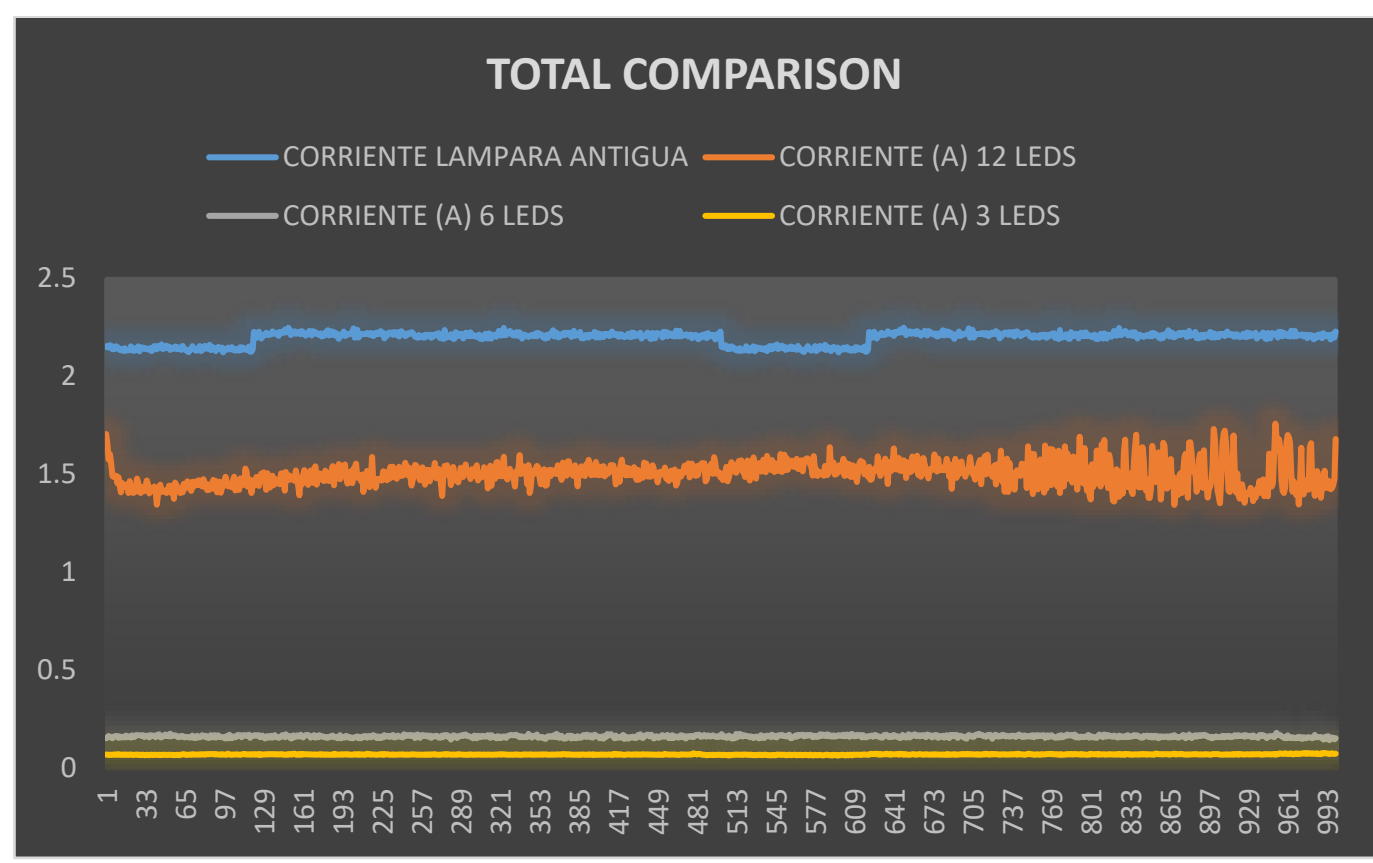

5 Comparison graph of conventional lamp and LEDs / Own source

Comparison of luxes of all the tests made in all the powers of our lamp, our conventional lamp when being connected, and our current lamp with led light.

\section{TOTAL COMPARISON}

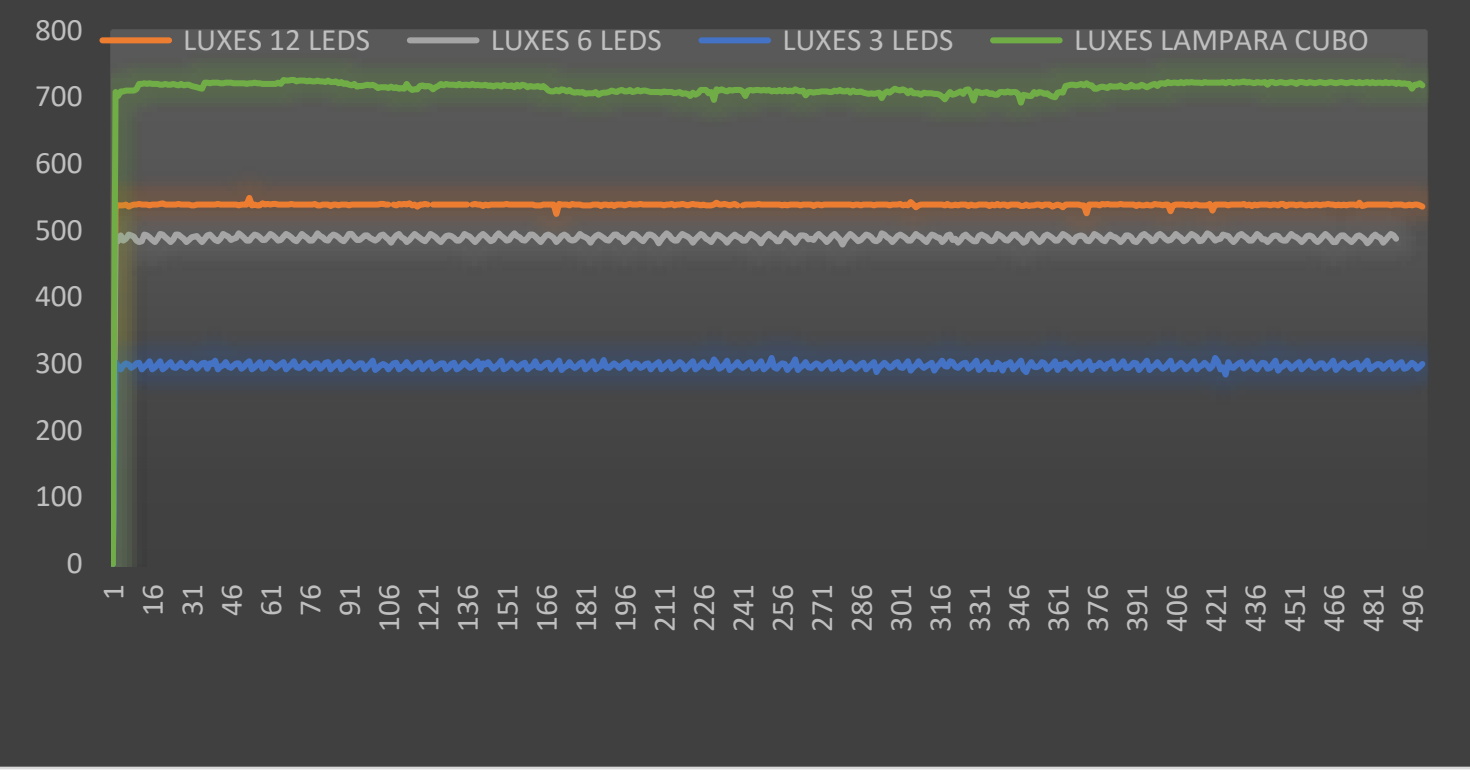

6 Total comparison chart / Own source

They were obtained through our experiments for the measurement of lux and current.

- If we are working with the SCT-013-030 sensor, it means that the output is in a +/-1V range, then the circuit that we will use is this: 


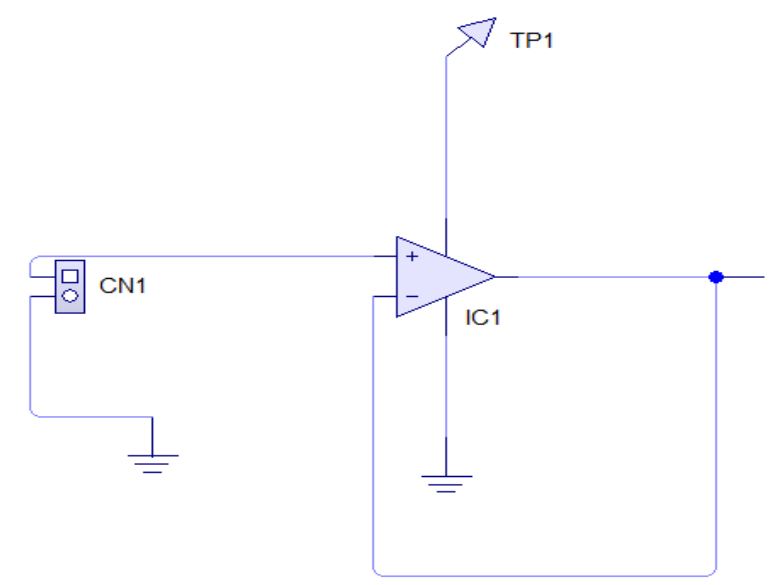

Illustration 7 Electrical diagram for measuring current / own source

Audio datasheet connector: We used it as a standard connector since it's easier to obtain analog data in an exact way; it helped to obtain values received from the current of both lamps to make the comparisons needed to finish the study.

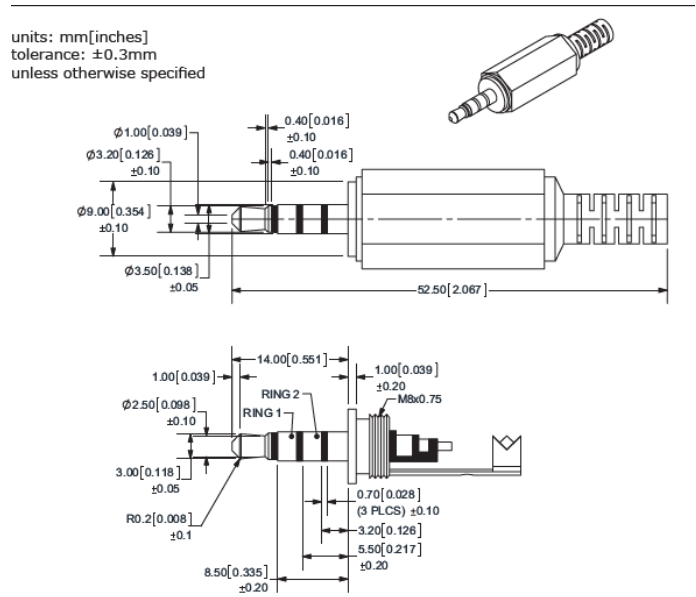

8 Audio plug datasheet / cuidevices.com

\section{Electric Scheme}

In an electrical diagram, the correct way to connect the circuit for measurement would be as follows (Illustration 7): 


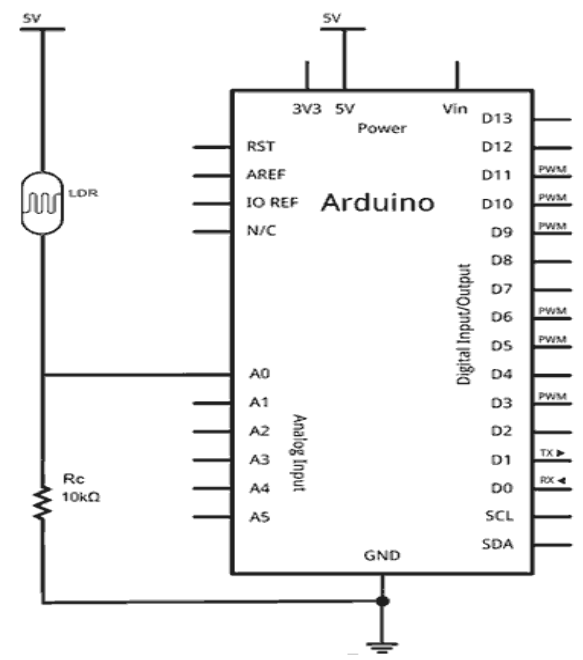

Illustration 9 Circuit to measure the illumination /Lluisllamas.es

Assembly

The electrical assembly on a protoboard would look like this:

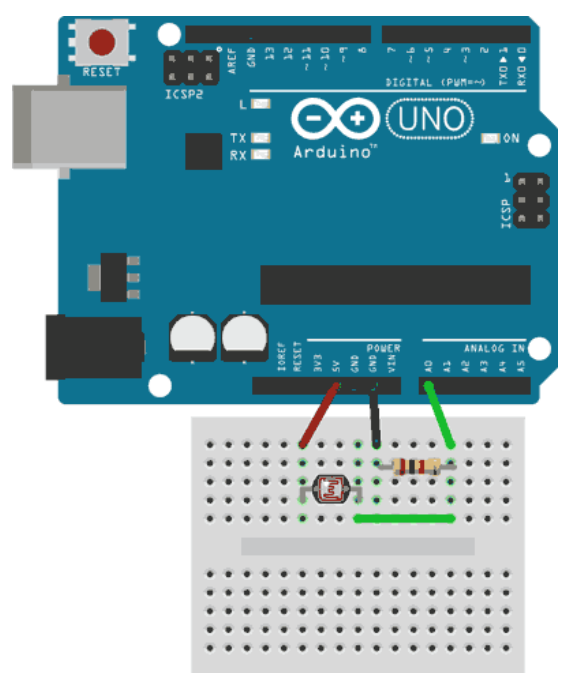

Illustration 10Circuit to measure light intensity (Microcontroller At mega 328) / Luisllamas.es

\section{References}

[1] DAZA, MARIA CANDELARIA, "IMPLEMENTACION DEL MODULO PARA LA MEDICION DE CALIDAD DE LA ENERGIA," IMPLEMENTACION DEL MODULO PARA LA MEDICION DE CALIDAD DE LA ENERGIA, p. 81, 2018.

[2] [Online].

[3] S. D. L. REPUBLICA, Gaceta del Senado, pp. LXIII/3SR-19/82389, Miercoles 11 Julio 2018.

[4] Grupo de Eco Eficiencia Energenita UCV., "ecoenergiaucv.blogspot," octubrre 2013. [Online]. Available: http://ecoenergiaucv.blogspot.com/p/blog-page_18.html.

[5] "Crisis del petróleo de 1973," 9 septiembre 2020. [Online]. Available:

https://es.wikipedia.org/wiki/Crisis_del_petr\%C3\%B3leo_de_1973. 


\section{Authors:}

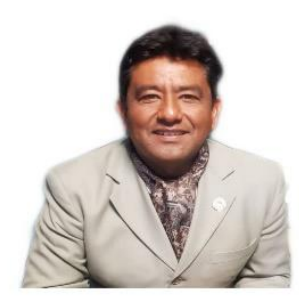

Miguel Terrón Hernández graduated from the Master's Degree in Engineering in Industrial Process Automation from the Polytechnic University of Puebla in 2012. He works as an independent consultant in Proactive Maintenance techniques, providing service in the central-eastern region of México from 2000 to date. He also works as a teacher at the Technological University of Tlaxcala in the career of Industrial Maintenance Engineer since 2012.

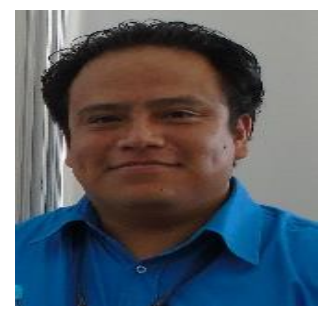

Jonny Carmona graduated in 2010 from the Electronic Engineering career at the Technological Institute of Apizaco with the specialty of Automation and Instrumentation. During 2010-2015 he worked as an Electrical Engineer in the company MIF developing electrical projects for the steel industry. Since 2013, he has been working as a teacher at the Technological University of Tlaxcala in the career of Industrial Maintenance.

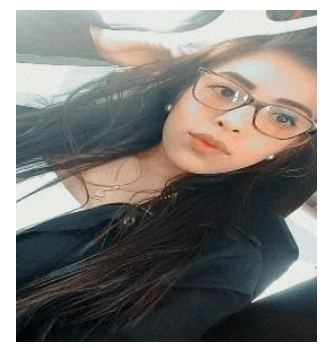

Brenda Bonilla Zetina graduated in 2019 from the Industrial Maintenance career as a technician at the Technological University of Tlaxcala, currently in 2020 she is studying Engineering at the same institution.

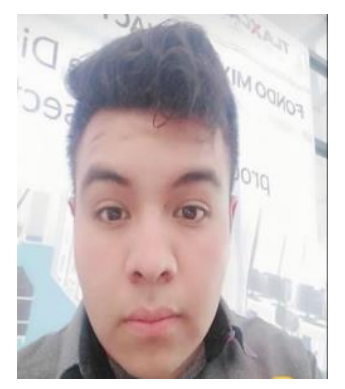

Alan Carmona Lopez graduated in 2019 from the Industrial Maintenance career as a technician at the Technological University of Tlaxcala, currently in 2020 she is studying Engineering at the same institution. 




Elisur Prado Luna graduated in 2019 from the Industrial Maintenance career as a technician at the Technological University of Tlaxcala, currently in 2020 she is studying Engineering at the same institution. 